\section{Dynamic expiratory airway collapse and evaluation of collateral ventilation with Chartis}

We thank Gesierich et $a l^{1}$ for raising some important issues regarding the evaluation of collateral ventilation using the Chartis flow catheter. In our review, we only provided two classical examples of Chartis expiratory flow and inspiratory pressure results; one from a patient with no collateral ventilation and another from a patient with significant collateral ventilation. ${ }^{2}$ However, in clinical practice, a range of findings are observed that sit in the 'grey zone'.

In our practice and the results from an open-label multicentre study of valves where collateral ventilation was assessed with the Chartis system, it is evident that adequate assessment was not possible in about $15 \%$ of patients. ${ }^{3}$ A variety of factors may be responsible. Blockage of the catheter by secretions or apposition of the catheter against the airway wall may also account for the abrupt cessation of flow and rapid increase in airway pressure. In some patients, anatomical factors are responsible for preventing an adequate seal with the balloon. The bronchoscopist should have an adequate view of the whole balloon within the lobar orifice to confirm that there is an adequate seal, especially in a patient where there is persistence of flow beyond $5 \mathrm{~min}$ with more than $250 \mathrm{~mL}$ exhaled over that period. This is a particular issue for the right upper lobe.

The situation described by Gesierich et al is more interesting. We agree that in both situations where there is either an abrupt cessation of flow (example A) or gradual cessation of flow (example B) in the context of low exhalation volumes (less than $100 \mathrm{~mL}$ ), the most likely mechanism is dynamic airway collapse distal to the balloon catheter. We would consider the majority of situations where less than $100 \mathrm{~mL}$ of air is exhaled as inconclusive and would use additional information such as evaluation of CT fissure integrity. The ipsilateral lobe should also be assessed by Chartis to further determine collateral ventilation status.

These cases emphasise the importance of adequate training and knowledge of the various factors, which can influence the measurement of collateral ventilation with the Chartis system. There are some

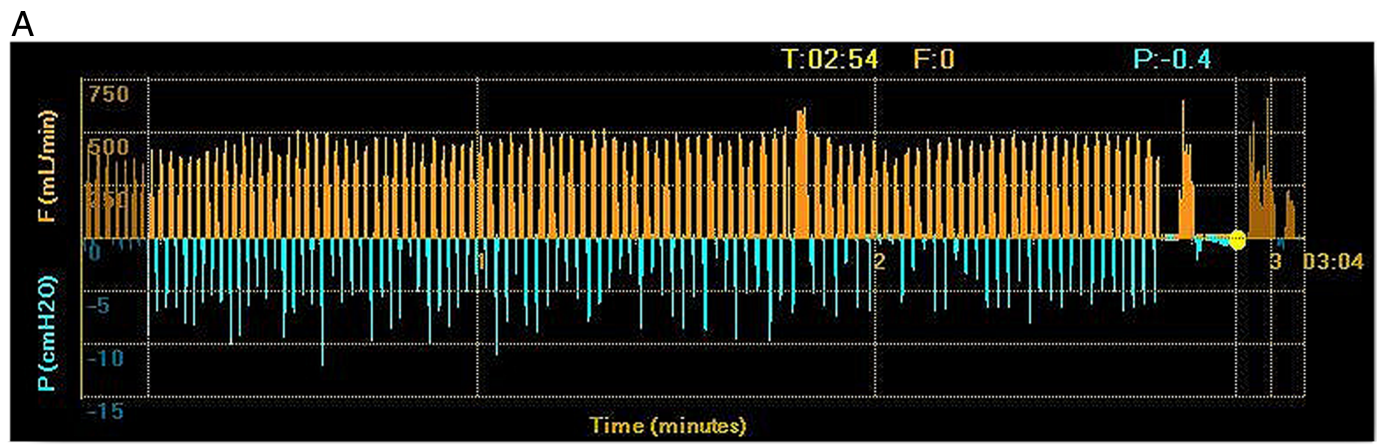

B

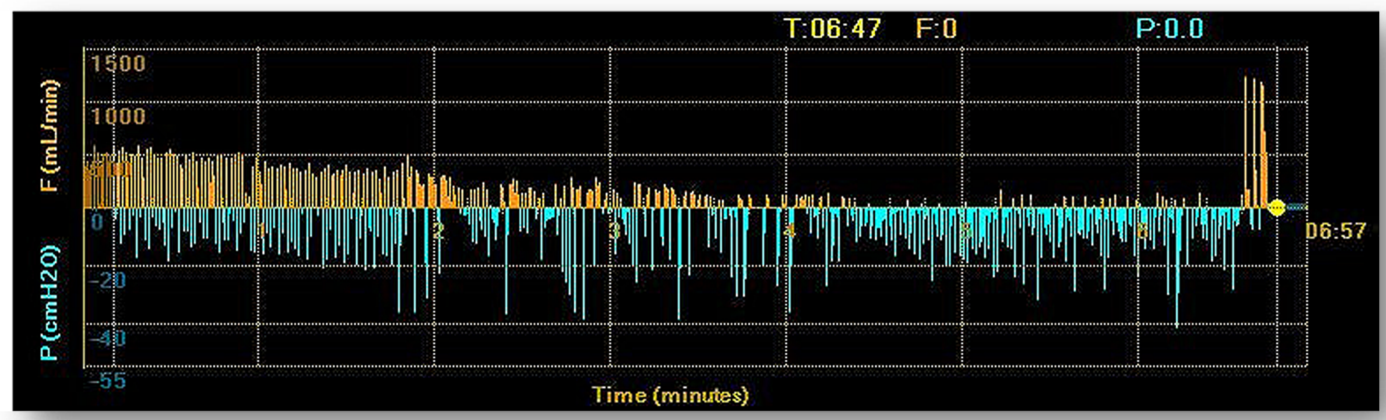

Figure 1 Measurement of collateral ventilation with the Chartis system (A) in the left upper lobe demonstrating persistence of flow suggesting the presence of collateral ventilation and (B) in the left lower lobe with gradual decrease in flow suggesting the absence of collateral ventilation. 


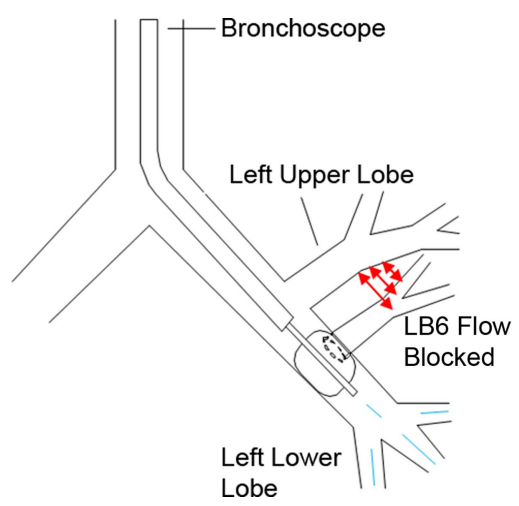

Figure 2 Position of the balloon catheter in the left lower lobe with obstruction of the apical segment of the lower lobe artificially preventing the collateral flow from this segment and hence providing a false reading.

important pitfalls in the measurement of collateral ventilation in the lower lobes. The following clinical scenario emphasises the subtlety in clinical practice. Measurement of collateral ventilation with Chartis in the left upper lobe suggested the presence of collateral ventilation (figure 1A). The clinician treating this patient also evaluated the left lower lobe and the impression was that there was no collateral ventilation in the left lower lobe (figure 1B). These measurements were followed by placement of endobronchial valves in the left lower lobe. However, clinical follow-up showed no clinically meaningful benefit and the patient did not develop atelectasis. On further consideration it is likely that occluding segment 6 (apical segment of the lower lobe) by the Chartis balloon leads to an artificial disruption of collateral ventilation flow (figure 2).

We thank Gesierich et al for raising these issues. The take home message is the need to concentrate developmental therapies in specialist centres working in multidisciplinary environments. A platform for training and mentorship is also an essential component of introducing these new techniques into clinical practice.

\section{Pallav L Shah, ${ }^{1,2,3}$ Felix J F Herth ${ }^{4,5}$}

${ }^{1}$ The NIHR Respiratory Biomedical Research Unit at Royal Brompton and Harefield NHS Foundation Trust and Imperial College, London, UK

${ }^{2}$ Chelsea \& Westminster Hospital, London, UK
${ }^{3}$ National Heart \& Lung Institute, Imperial College, London, UK

${ }^{4}$ Pneumology and Respiratory Care Medicine, Thoraxklinik, University of Heidelberg, Heidelberg, Germany

${ }^{5}$ Translational Lung Research Center, Heidelberg, Germany

Correspondence to Dr Pallav L Shah, Royal Brompton Hospital, Sydney Street, London SW3 6NP, UK; pallav.shah@ic.ac.uk

Contributors PLS and FJFH equally contributed to this letter.

Competing interests PLS and FJFH have participated in clinical trials on endobronchial valves and the Chartis system and the host institutions have been reimbursed for some clinical trial expenses by Pulmonx.

Provenance and peer review Commissioned; internally peer reviewed.

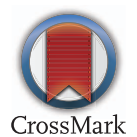

To cite Shah PL, Herth FJF. Thorax 2014;69:290-291.

Received 18 November 2013

Accepted 19 November 2013

Published Online First 19 December 2013

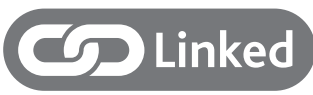

- http://dx.doi.org/10.1136/thoraxjnl-2013-203743

- http://dx.doi.org/10.1136/thoraxjnl-2013-204749

Thorax 2014:69:290-291.

doi:10.1136/thoraxjnl-2013-204875

\section{REFERENCES}

1 Gesierich W, Samitas K, Behr J. Determining collateral ventilation during bronchoscopy: unanswered questions Thorax 2014;69:289-90.

2 Shah PL, Herth FJ. Current status of bronchoscopic lung volume reduction with endobronchial valves. Thorax 2014;69:280-6.

3 Gompelmann D, Eberhardt R, Herth FJ. Collateral ventilation. Respiration 2013;85:515-20. 